ISSN 1112-9867

Available online at

http://www.jfas.info

\title{
GEOPHYSICAL INVESTIGATION ON THE FRACTURE DISTRIBUTION OF IWO-OLUPONA AREA SOUTH-WESTERN NIGERIA USING VLF-EM TECHNIQUES
}

\author{
L. A. Sunmonu, K. O. Suleman, I. T. Bello*, L. O. Tijani and A. O. Ogunbode
}

Department of Pure and Applied Physics, Faculty of Pure and Applied Sciences, Ladoke Akintola University of Technology, PMB 4000, Ogbomoso, Oyo state. Nigeria.

Received: 26 January 2017 / Accepted: 17 April 2017 / Published online: 01 May 2017

\begin{abstract}
This work uses Very Low Frequency Electromagnetic (VLF-EM) method to investigate the subsurface structure on a proposed Housing estate in Iwo, South-Western Nigeria with coordinates $7^{\circ} 36^{\prime} 36.3$ " $\mathrm{N}$ and Longitude $\approx 4^{\circ} 12^{\prime}$ 06.6” $\mathrm{E}$. The average VLF frequency employed during the field work is $20.8 \mathrm{kHz}$ with average signal strength of $17 \mathrm{dBm}$ and the measuring interval of $20 \mathrm{~m}$. The data obtained by the VLF-EM method were analysed by 2Dline Plotting. Raw real, R (In phase) and the imagining, I (quadrature) components were measured on the field. The Raw Real and filtered real data were plotted against stations on the same graph using excel, the graphs obtained are sinusoidal in shape with the peak indicating a conductive zones, resulting from weak geologic materials that may be due to fracture, joints, crack, and the trough indicates a non-conductive zones, associated with competent material which may be attributed to fresh basement material or resistive geological formation.
\end{abstract}

Key words: Fracture, conductive zone, weak zone, structural displacement, frequency

\footnotetext{
Author Correspondence, e-mail: itbello@student.lautech.edu.ng doi:http://dx.doi.org/10.4314/jfas.v9i2.9
}

\section{INTRODUCTION}

In recent years, the use of integrated geophysical method of investigations have found useful and increasing applications in many geological studies which ranges from shallow 
engineering studies, groundwater and mineral deposits explorations as well as in a variety of geo-environmental studies that includes investigations of contaminated sites or waste disposal areas [1-4]. High urbanization rate and urgent need for natural resources on one hand and non-invasive character of the geophysical methods such as geo-electrics, electromagnetic methods, very low frequency (VLF), and induced polarization (IP), which can provide information over larger areas, are said to expedite this trend [5-9].

As reported by Coker et al., 2009, the search for ground water is faced with lots of uncertainties. The use of the right exploration techniques in the delineation of subsurface water- bearing formations will in no little measure, minimize or avoid altogether, this uncertainties [10].

Bernstone et. al., 2000; Karlık and Kaya 2001; Oskooi and Pedersen, 2005 while solving various problems, have all used geo-electric and electromagnetic methods in their investigations to a greater precision and accuracy [11-13]. Saydam, 1981; Ligas and Palmoba, 2006; Babu et al., 2007 have all identified the VLF-EM, in respect of mineral exploration and related geological structures, as a well-known method for quick mapping of near surface geologic structures [14-16]. The work of Wright, 1988; McNeill and Labson, 1991 as well as that of many other researchers have shown that, when compared with other electromagnetic methods, the VLF-EM method is one of the most used and is adequately described [17-18].

The method uses radio signals from worldwide network transmitter stations which operate in frequency ranges of between $5 \mathrm{kHz}$ and $30 \mathrm{kHz}$. Chouteau et al., 1996; Gharibi and Pedersen, 1999 reported thatthe underlying principle of this method of survey is to exploit the fact that the ratio of the secondary vertical magnetic component to the horizontal primary magnetic field is a measure of conductivity/resistivity contrast since this tipper component is of internal origin of the anomalous body [19-20].

As a result of the above, VLF-EM technique have been employed in this study as the mapping tool with the overall objective of geophysical mapping for possible detection of buried subsurface structural features (such as fractures, quartz or pegmatite veins) in respect of fracture distribution prospects located at the outskirt of the study area (Iwo, Osun State) Nigeria. There is present evidence of fracture distribution within Iwo basement complex which is predominantly within a farmland grown with cassava at a coordinate of about $7^{\circ} 36^{\prime}$ $36.3^{\prime \prime} \mathrm{N}$ and Longitude $\approx 4^{\circ} 12^{\prime} 06.6^{\prime \prime} \mathrm{E}$. The study area (iwo-olupona)is located at $7^{\circ} 30^{\prime}-$ $7^{\circ} 36^{\prime} \mathrm{N}$ latitude and $3^{\circ} 40^{\prime}-4^{\circ} 12^{\prime} \mathrm{E}$ longitude. This region lies within the tropical rain forest of Nigeria that has two distinct seasons (wet, April-October; and dry, November- March). The 
annual mean rainfall is about $1,600 \mathrm{~mm}$. The diurnal range in temperature is not significant, but the daily temperature can reach $29{ }^{\circ} \mathrm{C}$ and is seldom lower than $25^{\circ} \mathrm{C}$. The water table in the region is generally found at less than $12 \mathrm{~m}$ in depth from the ground surface. The study is also partly intended to possible structural features (fractures and fresh basement rocks). The VLF-EM techniques are expected to provide information on the subsurface structural features in respect of fracture distribution potential in the study area and possible further localized geophysical investigation. The quantity and deposition of ground water depends on the geological characteristics of the host rock formation.

\section{RESULTS AND DISCUSSION}

In this research, the geophysical investigation on the fracture distribution of Iwo-Olupona Area South-western Nigeria Using VLF-EM Techniques is presented. The raw real (blue) in the graphs below indicate that the raw results observed from the field work which has been affected by some anomallies such as interference, noise, temperature inversion, near resitivity and so on while, the filtered real (pink) in the graphs below indicate that the anomallies that affected the raw data has been filtered. Also in the graphs below the positive peaks indicate conducting areas which may be due to faults zones, fractures zones and shears zonesWhile, the negative peaks indicate non - conducting which may be due to fresh basement. Peaks of the pinks are well defined because they are filtered, so the peaks of the pink graphs will be consider most in this discussion.

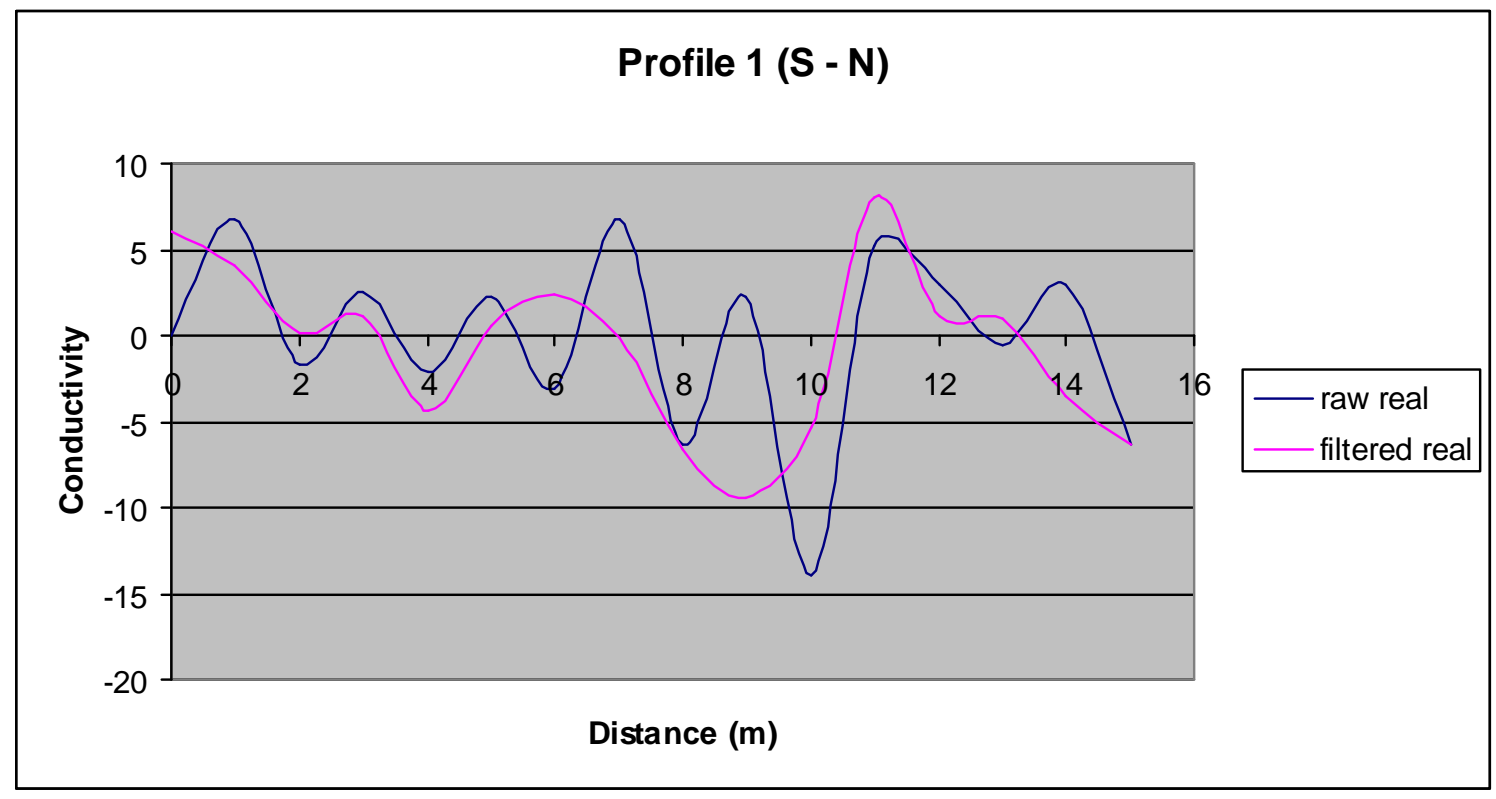

Fig.1. Profile 1(S - N); from the Southern part to the Northern part of the study Area 
Figure (1), shown the profile $1(\mathrm{~S}-\mathrm{N})$, the negative peak from $32 \mathrm{~m}$ to $50 \mathrm{~m}$ indicate non conducting area due to small fresh basement while, the broad positive peak from $50 \mathrm{~m}$ to $70 \mathrm{~m}$ indicate conducting area due to fractures of a large extension. Also the negative from $70 \mathrm{~m}$ to $102 \mathrm{~m}$ shows that the areas are non - conducting of a large fresh basement, while the positive peak from $102 \mathrm{~m}$ to $120 \mathrm{~m}$ indicate conducting area due to fracture of a sharp or shallow void and the areas are not suitable for any construction rather than ground water development.

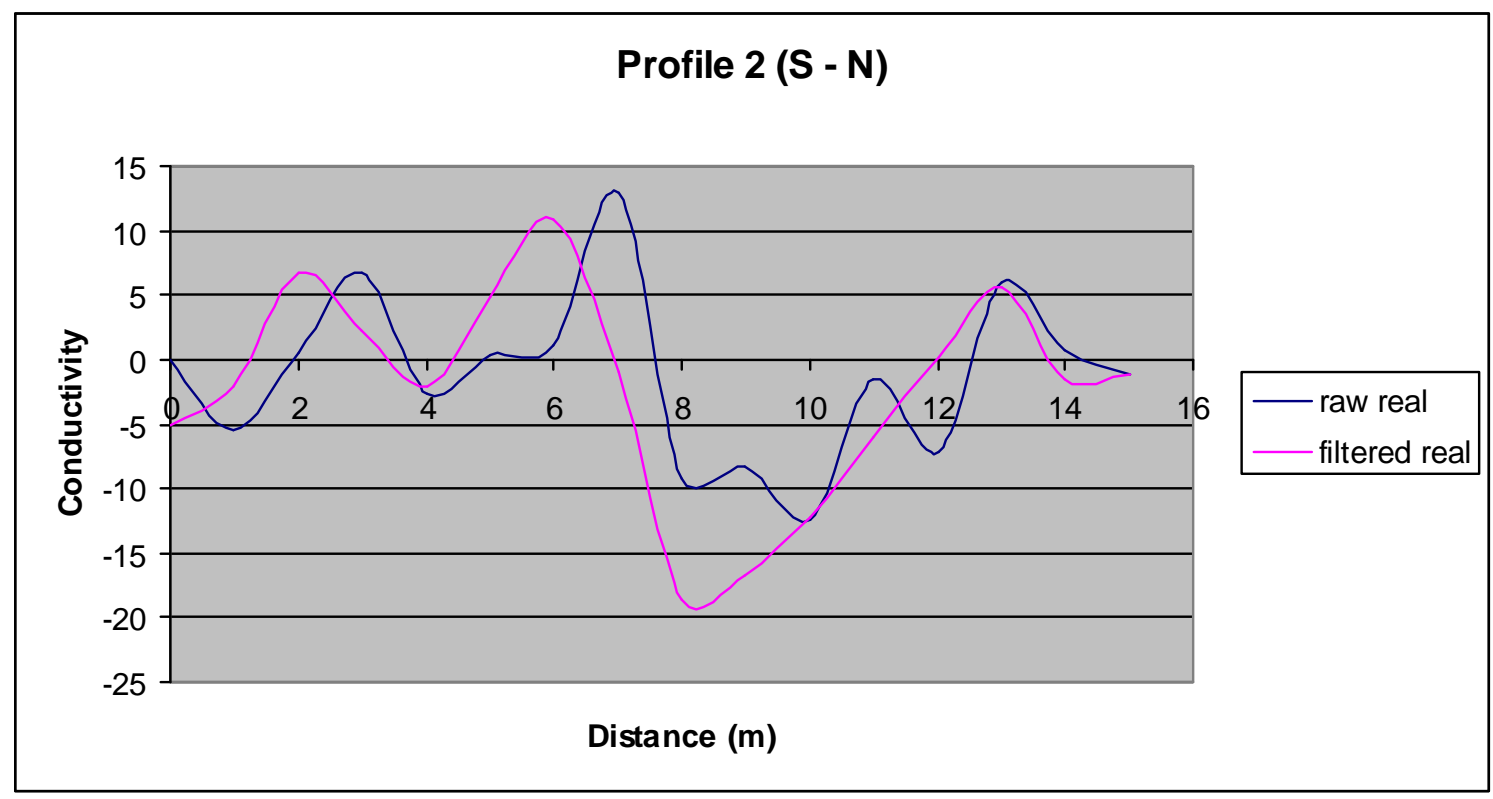

Fig.2. Profile 2(S - N); from the Southern part to the Northern part of the study Area

In Figure (2), which shown the profile $2(\mathrm{~S}-\mathrm{N})$, the positive peak from $16 \mathrm{~m}$ to $37 \mathrm{~m}$ indicate conducting or weak area due fault/ fracture zone while, the sharp positive peak from $42 \mathrm{~m}$ to $70 \mathrm{~m}$ indicate conducting area due to fractures and the areas are suitable for ground water development. Also the negative from $70 \mathrm{~m}$ to $120 \mathrm{~m}$ shows that the areas are non - conducting or non - weak zones of a large fresh basement, hard rock or near surface material while, the positive peak from $120 \mathrm{~m}$ to $139 \mathrm{~m}$ indicate conducting area due to fracture of a very narrow hole. 


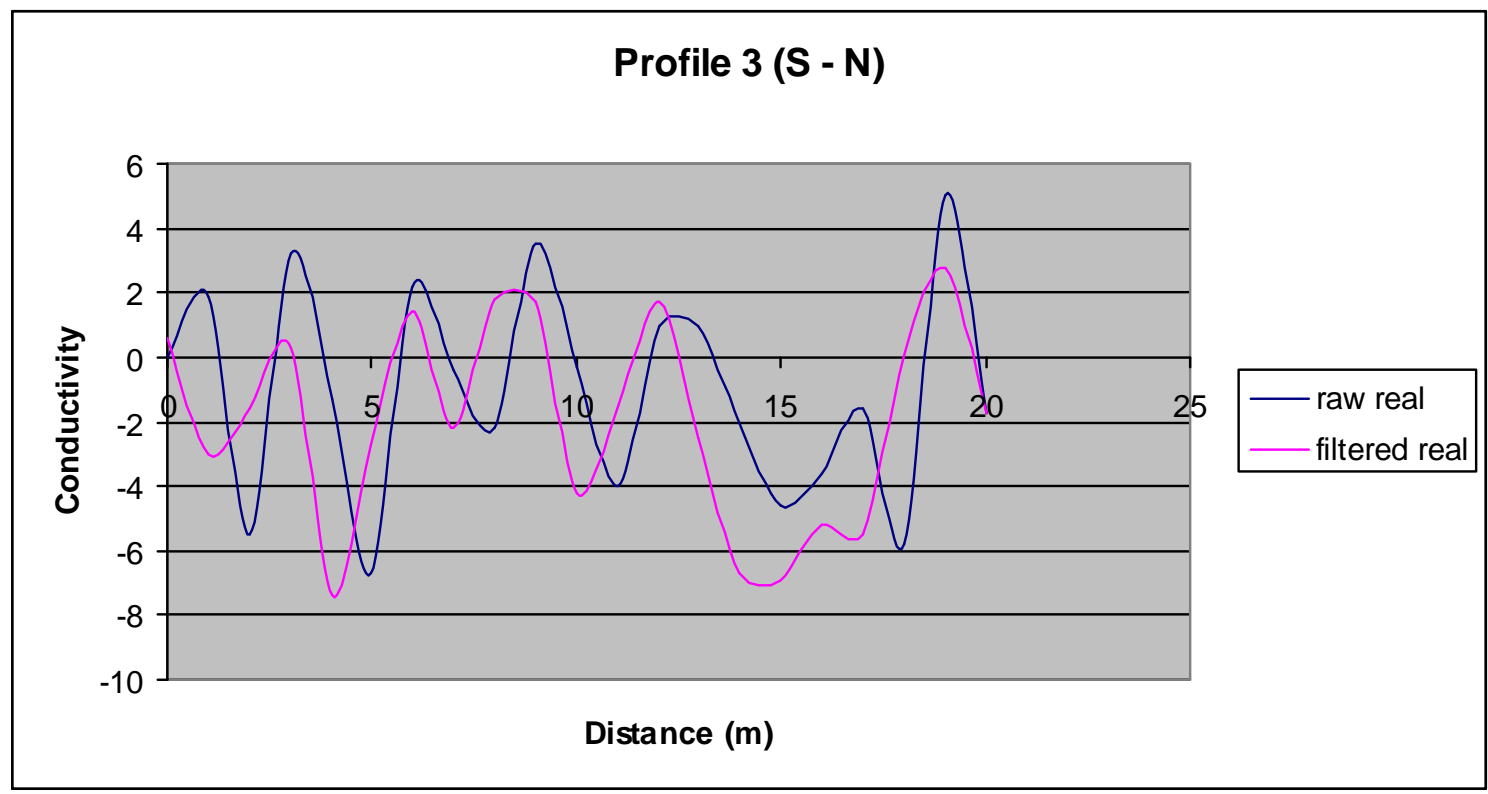

Fig.3. Profile 3(S - N); from the Southern part to the Northern part of the study Area

Figure (3), shown profile 3 (S - N), the negative peaks from 0 to $200 \mathrm{~m}$ are well distributed, this shows that the area non - conducting zones which may due to fresh rock basement While, the positive peaks from 0 to $200 \mathrm{~m}$ are conducting areas due to small fracture zones.

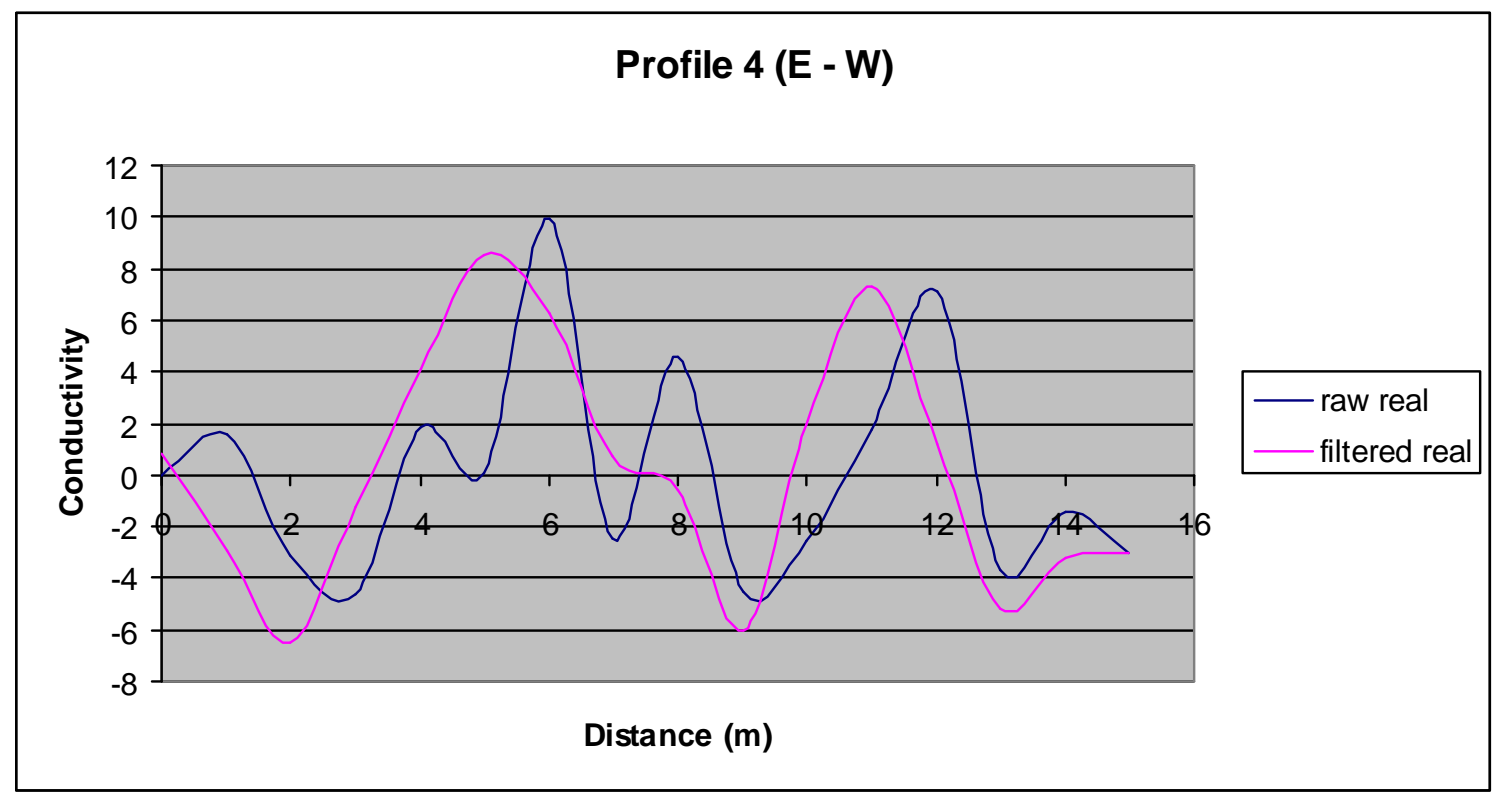

Fig.4. Profile 4(S - N); from the Eastern part to the Western part of the study Area

In Figure (4), that shown the profile $4(\mathrm{E}-\mathrm{W})$, the negative peak of sharp curves from $5 \mathrm{~m}$ to $31 \mathrm{~m}$ and from $80 \mathrm{~m}$ to $90 \mathrm{~m}$ indicate the non - conducting area due to large fresh rocks basement While, the positive peaks of sharp curves from $31 \mathrm{~m}$ to $80 \mathrm{~m}$ and from $90 \mathrm{~m}$ to $120 \mathrm{~m}$ 
indicate conducting area which may be due to fracture, fault and shears zones of large or shallow void, so these areas is good for groundwater development.

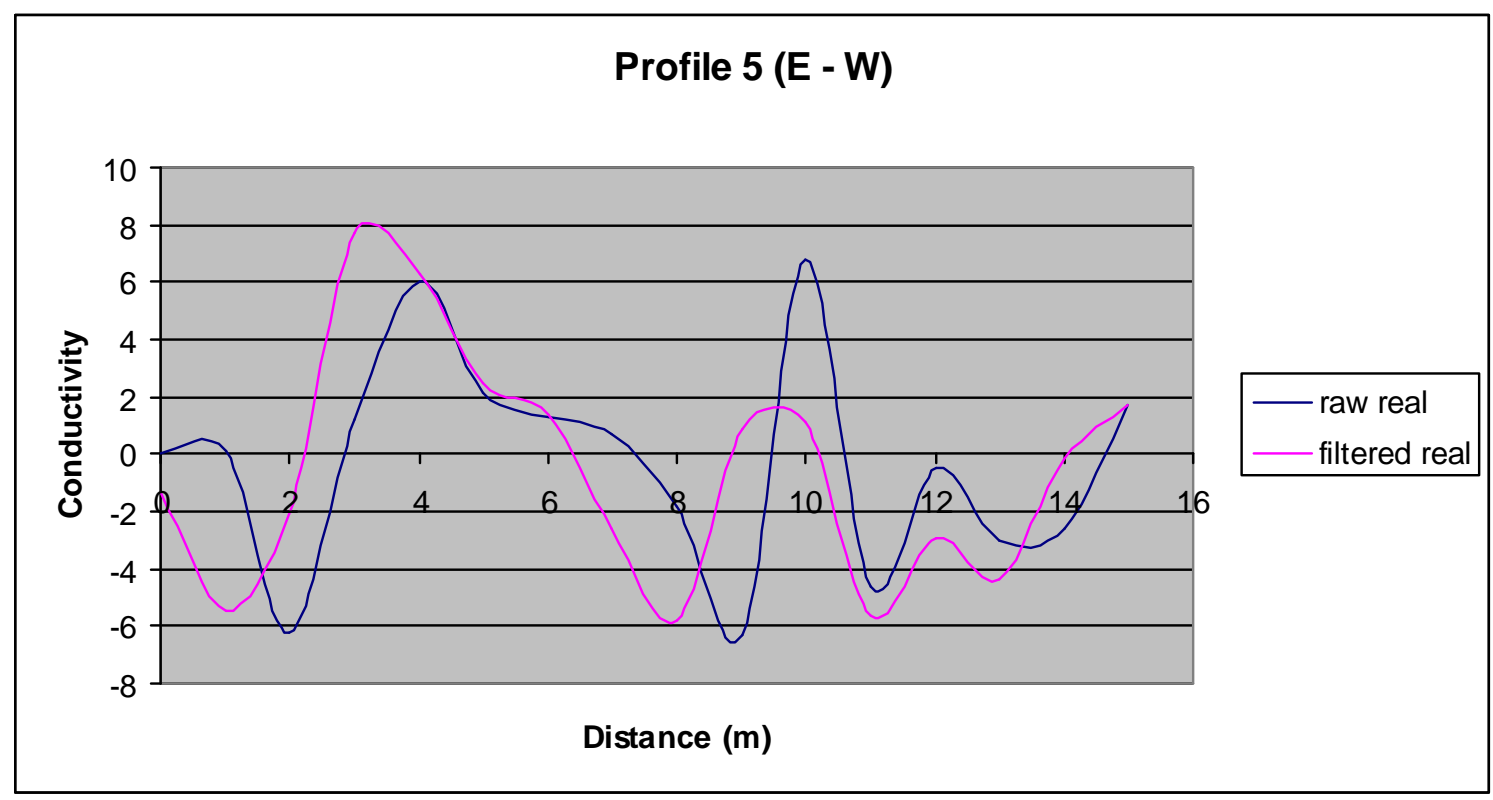

Fig.5. Profile 5(S - N); from the Eastern part to the Western part of the study Area

Figure (5), shown the profile $5(\mathrm{E}-\mathrm{W})$, the sharp positive peak from $21 \mathrm{~m}$ to $61 \mathrm{~m}$ are conducting or weak areas which may be due to fault or fractures zone of deep void and these areas remain the best area for groundwater exploration While, the negative peaks from 0 to $120 \mathrm{~m}$ shows the non - conducting area of fresh rock basement which may be good for engineering purpose such as construction of bridges, building e.t.c.

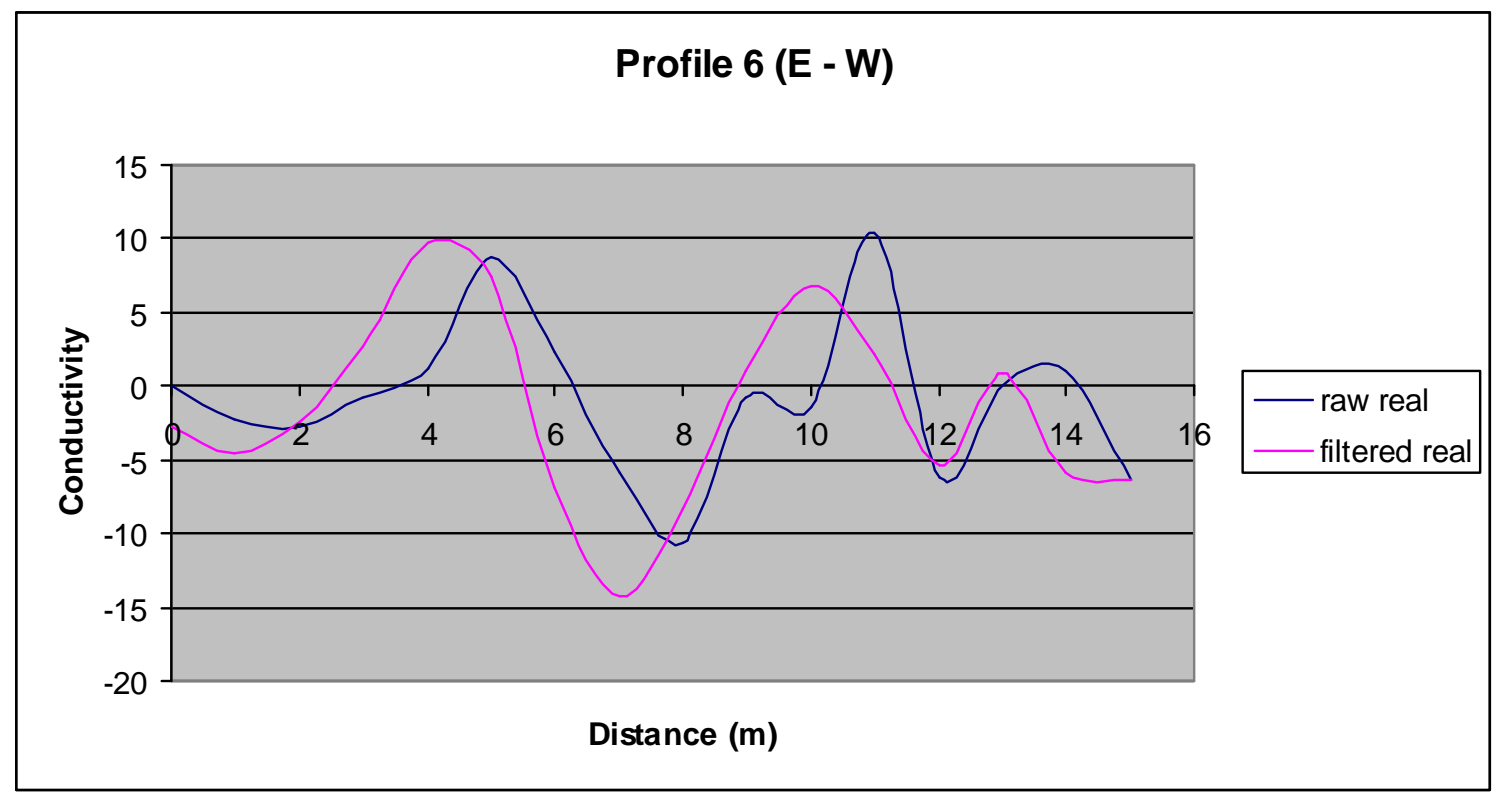

Fig.6. Profile 6(S - N); from the Eastern part to the Western part of the study Area 
Figure (6), shown the profile 6 ( $\mathrm{E}-\mathrm{W}$ ), the positive peaks from $22 \mathrm{~m}$ to $58 \mathrm{~m}$ and from $84 \mathrm{~m}$ to $116 \mathrm{~m}$ indicates conducting or weak area due to fracture distribution which may be good ground water development While, negative from o to $22 \mathrm{~m}$ and sharp curves peaks from $58 \mathrm{~m}$ to $84 \mathrm{~m}$ indicate non conducting areas which may be due to fresh rock basement, hard rock or near surface material.

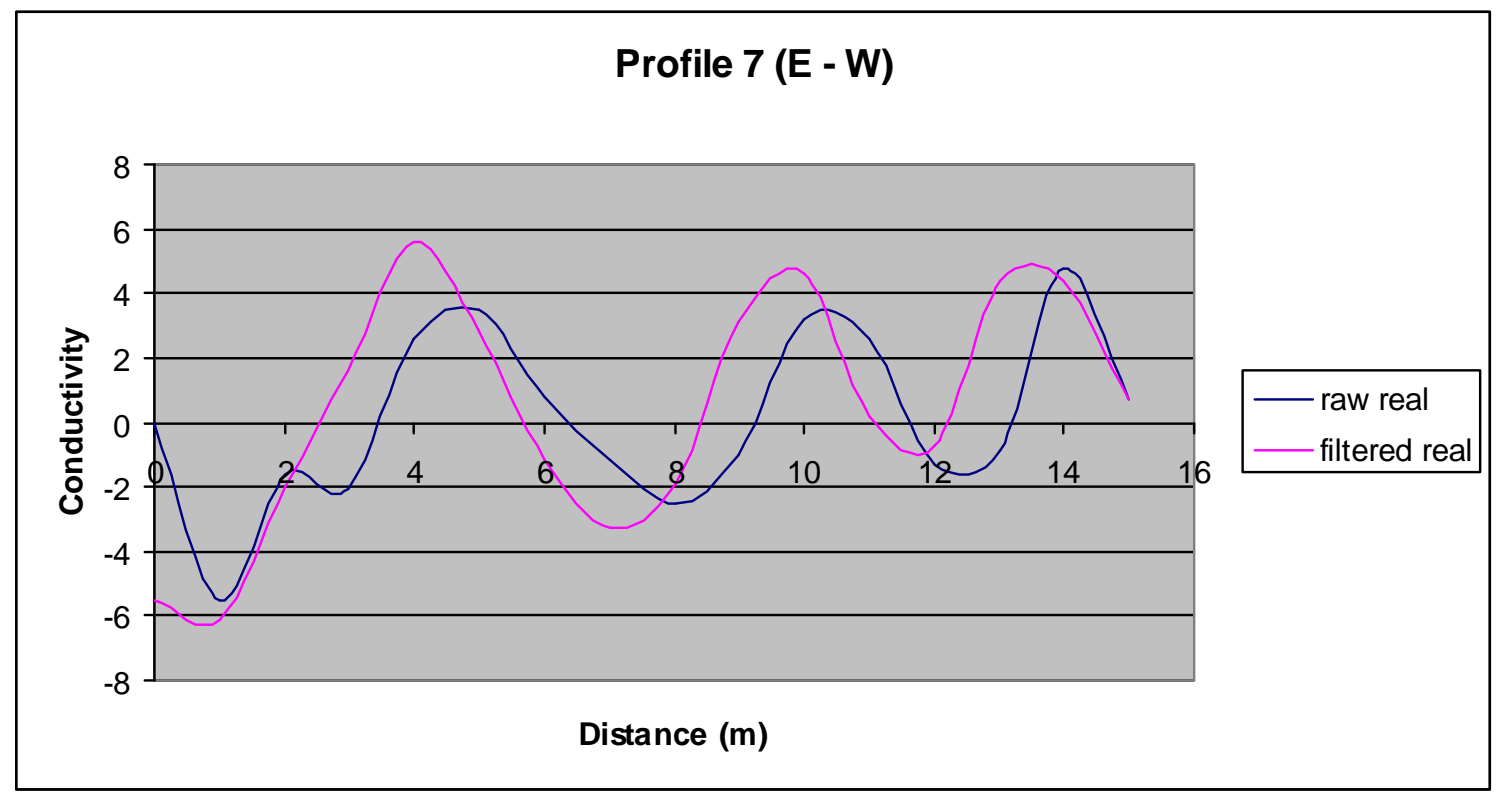

Fig.7. Profile 7(S - N); from the Eastern part to the Western part of the study Area Figure (7), also shown the profile 7 (E - W), the positive peaks from $22 \mathrm{~m}$ to $59 \mathrm{~m}$, from $82 \mathrm{~m}$ to $115 \mathrm{~m}$ and from $120 \mathrm{~m}$ to $145 \mathrm{~m}$ of relatively the same peaks indicate conducting areas which shows that the deep fracture are evenly distributed While, the negative peaks from 0 to $120 \mathrm{~m}$ indicate non - conducting areas due to fresh basement of rocks, hard rock or near surface material like magnetic intrusive.

\section{MATERIALS AND METHODS}

The research carried out in this work was performed using ABEM WADI equipment (plate1). The raw real VLF were converted with the aid of an in-built filtering program provided in the ABEM WADI equipment as well as a software package (KHF filt version 1.0, pirttijarvi 2004), into filtered real data in which an anomaly infection appear as peak positive anomalies and false VLF anomaly infection as negative anomalies of the profiles. The average VLF frequency in the field work was $20.8 \mathrm{kHz}$ with the average signal strength of $17 \mathrm{dBm}$ and the measuring interval of $20 \mathrm{~m}$. The Raw Real and filtered real against stations where plotted on the same graph using excel, the graph are inform of sinusoidal graph, its peak is conductive or weak zone and the through of the graph is non-conductive or non-weak 
zone.

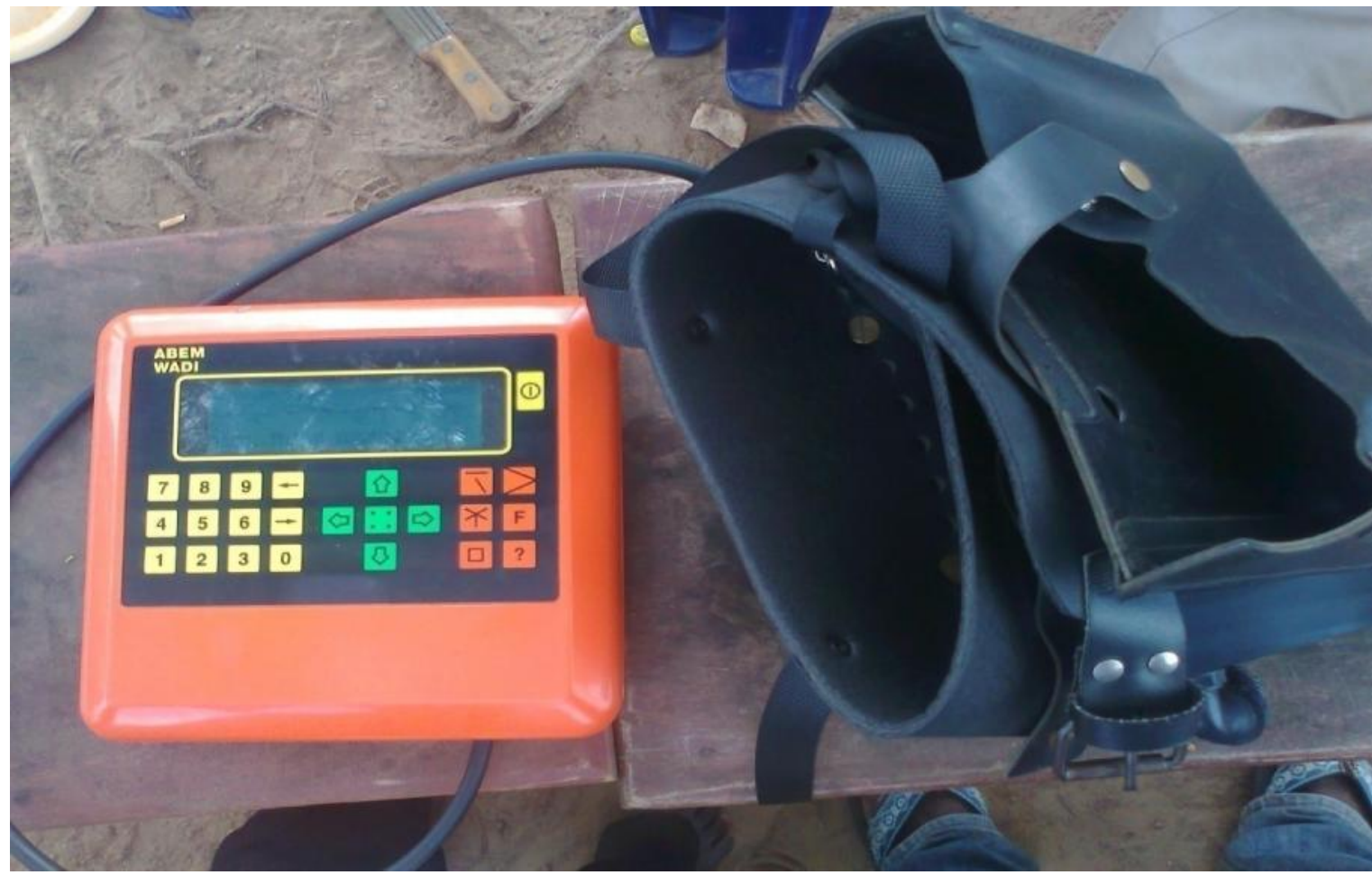

Plate 1: ABEM WADI INSTRUMENT AND GADGET

\section{CONCLUSION}

This research revealed an even distribution of deeper fracture in the east western part of the study area which remain the best area for groundwater development while the remaining part are suited for good structural construction such as bridges constructions, buildings and so on. This shows that the initial designated of the study area as a residential site remain the best which shall enable the residence to construct buildings and drilling of borehole for domestic purpose.

\section{REFERENCES}

[1] Olorunfemi, M. O. \& Mesida, E. A. (1987): Engineering geophysics and its application in engineering site investigation-Case study from Ile-Ife area. The Nigerian Engineer, Vol.22, pp. 57-66.

[2] Sharma, P. V. (1997): Environmental and Engineering Geophysics, Cambridge University Press, 173p.

[3] Frohlich, R. K. \& Parke, C. D. (1989): The electrical resistivity of the vadose zone field study. Groundwater; Vol. 27, No. 4, pp. 524-530. 
[4] Steeples, D.W. (2001): Engineering and environmental geophysics at the millennium. Geophysics; Vol. 66, pp. 31-35.

[5] Frohlich, R. K., Urish, D. W., Fuller, J., O'Reilly, M. (1994): Use of geoelectrical methods in groundwater pollution surveys in a coastal environment. Jour. Appl. Geophysics; Vol. 32, pp. 139-154.

[6] Dahlin, T. (1996): 2D resistivity surveying for environmental and engineering applications. First Break; Vol. 14, pp. 275-284.

[7] Aristodemu, E., Thomas-Betts, A. (2000): DC resistivity and induced polarization investigations at a waste disposal site and its environments. Jour. Appl. Geophysics; Vol. 44, pp. 275-302.

[8] Draskovits, P., Vero, L. (2005): Indication of groundwater contamination with the induced -polarization (IP) method. In: Butler, Dwain K. (Ed.), Near-Surface Geophysics. SEG Tulsa, OK, pp. 551-561.

[9] Gokturkler, G., Balkaya C., Erhan, Z. \& Yurdakul, A. (2008): Investigation of a shallow alluvial aquifer using geoelectrical methods: a case from Turkey. Environ Geology; Vol. 54, pp. 1283-1290.

[10] Coker JO, Makinde V, Olowofela JA (2009): Geophysical Investigation of Groundwater Potentials of Oke-Badan Estate, Ibadan, Southwestern, Nigeria. Proceedings of $3^{\text {rd }}$ International Conference on Science and National development University of Agric. Abeokuta , p119.

[11] Bernstone, C., Dahlin T., Ohlsson T. \& Hogland, W. (2000): DC-resistivity mapping of internal landfill structures: two pre-excavation surveys. Environ Geol; Vol. 39, pp.360371.

[12] Karlık, G. \& Kaya, M. A. 2001. Investigation of groundwater contamination using electric and electromagnetic methods at an open waste-disposal site: a case study from Isparta, Turkey. Environ Geology; Vol. 40, pp. 725-731.

[13] Oskooi, B., Pedersen, L. B. (2005): Comparison between VLF and RMT methods. A combined tool for mapping conductivity changes in the sedimentary cover. Jour. Appl. Geophysics; 57, pp. 227-241.

[14] Saydam, A. S. (1981): Very low-frequency electromagnetic interpretation using tilt angle and ellipticity measurements Geophysics; Vol. 46, pp.1594-1605.

[15] Ligas, P., Palmoba, M. (2006): An integrated application of geological- geophysical methodo-logies as a cost-efficient tool in improving estimation of clay deposit potential: Case study from South-Central sardine (Italy). Ore Geology Reviews; Vol. 29, pp. 162-175. 
[16] Babu, R. V., Ram, S. \& Sundararajan, N. (2007): Modeling and inversion of magnetic and VLF-EM data with an application to basement fractures: A case study from Raigarh, India. Geophysics; Vol. 72, B133-B140.

[17] Wright, J. L. (1988): VLF interpretation manual. EDA Instrument, Toronto, Ontario, Canada.

[18] McNeill, J. D., Labson, V. F. (1991): Geological mapping using VLF radio fields. In: Nabighian, M.C. (Ed.), Geotechnical and Environmental Geophysics, Review and Tutorial, Vol. 1, Society of Exploration, Tulsa, pp. 191-218.

[19] Chouteau, M., Zhang, P., Chapellier, D. (1996): Computation of apparent resistivity profiles from VLF-EM data using linear filter. Geophysical Prospecting; Vol. 44, pp. 215212.

[20] Gharibi, M., Pedersen, L. B. (1999): Transformation of VLF data into apparent resistivities and phases .Geophysics; 64, pp. 1393-1402.

\section{How to cite this article:}

Sunmonu L. A. Suleman K. O. Bello I. T. Tijani L. O. Ogunbode A. O. Geophysical investigation on the fracture distribution of iwo-olupona area south-western nigeria using vlfem techniques. J. Fundam. Appl. Sci., 2017, 9(2), 736-745. 